\title{
Gaming well: links between videogames and flourishing mental health
}

\author{
Christian M. Jones ${ }^{1}{ }^{*}$, Laura Scholes ${ }^{1}$, Daniel Johnson ${ }^{2}$, Mary Katsikitis ${ }^{1}$ and Michelle C. Carras ${ }^{3}$ \\ ${ }^{1}$ Faculty of Arts and Business, University of the Sunshine Coast, Maroochydore, QLD, Australia \\ 2 Science and Engineering Faculty, Queensland University of Technology, Brisbane, OLD, Australia \\ ${ }^{3}$ School of Public Health, Johns Hopkins University, Baltimore, MD, USA
}

Edited by:

Steven E. Mock, University of

Waterloo, Canada

Reviewed by:

Matthew Schlesinger, Southern

Illinois University, USA

Courtney Plante, University of

Waterloo, Canada

${ }^{*}$ Correspondence:

Christian M. Jones, Faculty of Arts

and Business, University of the

Sunshine Coast, Locked Bag 4,

Maroochydore, OLD 4558, Australia

e-mail:cmjones@usc.edu.au
This paper is a review of the state of play of research linking videogaming and flourishing, and explores the role of videogames and technology to improve mental health and wellbeing. Its purpose is to develop understandings about the positive intersection of gaming and well-being, to document evidence regarding links between videogames and positive mental health, and to provide guidelines for use by other researchers as they design and use tools and games to improve mental health and well-being. Using Huppert's (Huppert and So, 2013) proposition that to flourish is more than the absence of mental disorder but rather a combination of feeling good and functioning effectively, resulting in high levels of mental well-being, and Seligman's (Seligman, 2011) PERMA theory of well-being, the paper identifies strengths in existing games that generate positive affect, positive functioning, and positive social functioning, contributing to, and supporting mental health and well-being.

Keywords: videogames, mental health, well-being, PERMA, Seligman, flourishing

\section{INTRODUCTION}

Flourishing mental health has been defined as a combination of feeling good and functioning effectively resulting in high levels of mental well-being. To flourish is more than the absence of disorder with flourishing conceived as the opposite of mental disorder rather than its mere absence (Huppert and So, 2013). Mental disorders are universal and present in all people of all countries (World Health Organisation, 2001) and it is imperative that society gains a better understanding, enabling and encouraging flourishing to be achieved (Keyes, 2002; Seligman, 2011; Huppert and So, 2013). Responding to concerns about the wellbeing of young people and emerging evidence of positive impacts of videogames this paper explores the state of play of research linking videogame play and flourishing mental health. Young people have increasing access to computers and videogames with gaming environments moving from predominantly solitary states to multi player environments. "Videogames", within the context of this paper, refers to electronic/digital games played on personal computers, home consoles (e.g., Microsoft Xbox, Sony Playstation, Nintendo Wii), tablets (e.g., iPads), mobile devices (e.g., smart phones, handhelds like Nintendo 3DS), and the web (e.g., via facebook or other websites). This review of the state of play of research linking videogaming and flourishing, and the role of videogames and technology, considers the potential of videogames to enhance mental health and well-being. While the paper focuses on the potential positive effects of videogaming, within the literature there has been a long history of highlighting the negative effects of videogames, and this contribution is duly noted.

\section{NEGATIVE EFFECTS OF VIDEOGAME PLAY}

Traditionally, much of the research on videogames has focused on the negative effects of playing such games, and in particular the effects of playing violent videogames. This research has provided insights into the ways that pre-existing characteristics may lead to some young people being vulnerable to negative impacts of videogames although further research is needed. Increasingly, the impact of violent videogames is being considered from a more nuanced perspective with an understanding that publication bias and the emphasis on the use of laboratory measures of aggression may exaggerate relationships between videogame violence and aggression, and not accurately predict real life behavior (Sherry, 2004, 2007; Ferguson, 2007; Kutner and Olson, 2008; Boyle et al., 2011). Various studies focus on longitudinal measures that attempt to demonstrate causal relationships between violent videogames and aggression. Many of these studies rely on self-reported measures of aggressive feelings or attitudes (Shibuya et al., 2008; Möller and Krahé, 2009; Anderson et al., 2010; Lemmens et al., 2011), while other studies include self-reported counts of aggressive behaviors (Shibuya et al., 2008; Bucolo, 2011), or combined teacher and peer ratings (Gentile and Gentile, 2008). While some of these studies do report associations between earlier violent videogame play and later self-reported aggression (Möller and Krahé, 2009; Anderson et al., 2010; Bucolo, 2011), or combined peer-and teacher-reported aggression (Gentile and Gentile, 2008), others do not support long-term direct effects of violent videogames on self-reported physical aggression (Shibuya et al., 2008; Lemmens et al., 2011). Interestingly, violence has been found not to be an important factor in contributing to game enjoyment as players play violent games for the same reasons they play other games, such as enjoyment of the challenge and the freedom to act in a virtual world (Przybylski et al., 2009a).

In a similar manner there have been studies concerned with pathological gaming. Longitudinal research on pathological gaming, however, is relatively scarce. One study examined the 
psychosocial causes and consequences of pathological gaming among adolescents, finding lower psychosocial well-being was generally an antecedent of pathological gaming (Lemmens et al., 2011). Diminished social competence, increased loneliness, and lower self-esteem were linked to an increase in pathological gaming six months later (Lemmens et al., 2011). Findings suggest that lower psychosocial well-being was more likely to be a cause rather than a consequence of pathological gaming (Chak and Leung, 2004; Ko et al., 2005). Studies on small groups of players who spend excessive amounts of time on games have shown that symptoms of addiction can arise including withdrawal, preoccupation, loss of control, and interpersonal or intrapersonal conflicts (Grüsser et al., 2007; Gentile, 2009), however, other studies fail to support links between heavy play and negative psychosocial outcomes in non-addicted gamers (Lemmens et al., 2011; Van Rooij et al., 2011).

While the negative effects of playing videogames are well documented, many of the potential problematics of gameplay appear associated with excessive amounts of time immersed in play and links to existing lower psychosocial well-being. These findings suggest consideration of the negative and positive effects of videogame play is warranted. This said, there remains a gap in literature that explores the potential positive outcomes of moderate videogame play including the many creative, social, and emotional benefits from playing videogames, including violent games (Ryan et al., 2006; Kutner and Olson, 2008; Wang et al., 2008; Przybylski et al., 2009a; Allahverdipour et al., 2010). Considering the potential of videogames for enhancing positive well-being is the focus of the following sections.

\section{VIDEOGAMES FOR POSITIVE WELL-BEING}

Recently, there has been significant interest in the links between videogame play and positive well-being (see Durkin and Barber, 2002; Barr et al., 2006; Colwell, 2007; Ryan and Deci, 2008; Wang et al., 2008; Hull, 2009; Allahverdipour et al., 2010; Boyle et al., 2011; Przybylski etal., 2011; Snodgrass et al., 2011b). There is also increased concern that the potential value of videogames has not been sufficiently considered particularly in terms of the benefits for young people at risk (Kutner and Olson, 2008). Existing literature on gaming has been inconsistent and has often focused on aggression. However, over the last five to ten years, increasing attention has been given to the possibility of games improving health and well-being (Desai et al., 2010). A number of studies reflect this shift and consider a nuanced approach to the positive and negative influences of game play with a number of significant studies demonstrating clear benefits to individuals who spend time in game play. As contemporary research provides examples of the benefits of gaming, the question becomes more about optimal levels of game play, the influence of factors such as gender, subgroups, and associated experiences, and the interplay of particular genres on well-being.

Studies focusing on the potential positive outcomes of videogame play have found links to positive emotions for players (Ryan et al., 2006; Kutner and Olson, 2008; Wang et al., 2008; Przybylski et al., 2009a; Allahverdipour et al., 2010). Moderate videogame play has been found to contribute to emotional stability
(Przybylski et al., 2011) and reducing emotional disturbances in children (Hull, 2009). Significantly, videogame play has been advocated as a means of relaxation and stress reduction by regular players (Russoniello et al., 2009; Wack and Tantleff-Dunn, 2009; Snodgrass et al., 2011b). Children playing games have reported "letting off steam" in response to problems with friends or parents with feelings of anger, guilt, or frustration dissipating after time spent in game play resulting in players feeling much happier (Colwell, 2007). Interestingly, depressed mood has been found to be significantly lower in moderate players of videogames compared to those who "never" play videogames and those who play videogames to excess (Durkin and Barber, 2002), and time spent in gameplay is highlighted as the moderating factor. Videogame play has also been linked to the development of skill acquisition (Gee, 2008; Johnson et al., 2011), and has been found to contribute to individual attitude and behavior changes (Baranowski et al., 2008; Burns et al., 2010). While videogames have been shown to provide a range of positive outcomes the focus of this paper is on links between videogaming and flourishing mental health as this association has previously not been clearly articulated.

\section{FLOURISHING MENTAL HEALTH}

Flourishing adults demonstrate high levels of emotional wellbeing, are happy and satisfied, tend to see their lives as having a purpose, feel some degree of mastery and accept all parts of themselves (Keyes, 2002). Furthermore, they have a sense of personal growth and have a sense of autonomy and an internal locus of control, choosing their fate in life instead of being victims of fate (Keyes, 2002). To explore the potential of videogame play in enhancing well-being this review considers positive research findings within Seligman's positive psychology model for well-being (Seligman, 2011). Seligman's model of well-being contains five elements: Positive emotion; Engagement; Relationships; Meaning and purpose; and Accomplishment (PERMA). Using Seligman's PERMA positive psychology model we have reviewed research linking videogames and flourishing mental well-being.

\section{POSITIVE EMOTION}

The ability, opportunity, and experience of feeling positive emotions such as happiness, satisfaction, joy, and the many other descriptors of good feelings.

\section{ENGAGEMENT}

The opportunity to be fully engaged and completely immersed in activities. To be engaged is to be so immersed in an activity that you lose your sense of time and feel boundless energy.

\section{RELATIONSHIPS}

The nature of a person's relationships strongly correlate to their happiness, health, and overall well-being. Improving relationships can bring greater happiness.

\section{MEANING}

Having meaningful activities brings a sense of purpose and fulfillment to daily life. A sense of purpose often accompanies activities which contribute to something larger than self. 


\section{ACCOMPLISHMENT}

Having goals and objectives to accomplish brings a sense of achievement and satisfaction to life, contributing to the feeling of well-being. This is the sense of satisfaction experienced when checking off tasks from a daily to-do list.

The awareness of PERMA can help increase well-being by focusing on combinations of feeling good, living meaningfully, establishing supportive and friendly relationships, accomplishing goals, and being fully engaged with life. We argue that videogames are an environment for nurturing these experiences that can help players go beyond surviving to really flourishing in life.

\section{VIDEOGAMES, PERMA AND WELL-BEING}

We propose that videogames, by their very nature, have design elements aligned with attributes of well-being, and that playing videogames can provide opportunities for flourishing mental health. This paper fills a gap in literature by explicitly reviewing emerging research to examine the positive outcomes of videogaming (Kutner and Olson, 2008; Allahverdipour et al., 2010). This review is timely as videogame use is widespread. Over 95\% of homes with children under the age of 18 have a device for playing videogames, and 94\% of children aged between 6 and 15, and $90 \%$ of people aged 16 to 25 play videogames (Brand, 2012). In 2005 the average age of a gamer was 24, in 2011 this average age rose to 32 (Brand, 2012). Videogames are no longer a solitary activity with $70 \%$ of players playing videogames with others either in the same room or over the internet (Brand, 2012). There have also been changes in terms of female gaming and in the 7 years from 2005 to 2011, the proportion of gamers who were female increased steadily from 38 to $47 \%$ with equal representation of female gamers to males predicted to be imminent (Brand, 2012). Therefore any mental health gains experienced by gamers could be increasing, and widespread. With the significance of the potential benefits of positive gameplay foremost, the following section details emerging research within the PERMA model.

\section{POSITIVE EMOTION}

Emerging research suggests that moderate game play can contribute to positive emotions (Ryan et al., 2006; Kutner and Olson, 2008; Wang et al., 2008; Przybylski et al., 2009a; Allahverdipour etal., 2010) and emotional stability (Przybylski et al., 2011). Positive mental well-being has also been associated with game play as a means of relaxation and stress reduction (Russoniello et al., 2009; Wack and Tantleff-Dunn, 2009; Snodgrass et al., 2011b). The amount of game play, however, is a moderating factor on the player's personal well-being. Durkin and Barber's (2002) examination of the relationship between game play and several measures of adjustment for 1304 high school students, found that videogame play was unlikely to be harmful and instead was often associated with positive outcomes. There were advantages for those adolescents who occasionally played videogames (low use) and those who played daily (high use) compared to the young people who reported that they never played games (never; Durkin and Barber, 2002). Specifically, depressed mood was significantly lower in the "low" use group compared to the "never" and "high" groups who reported similar outcomes. Self-esteem was also higher in the "low" use group with self-concept regarded higher by players than non players, with "high" use players scoring the highest in this domain. Both groups of players also reported higher levels of family closeness and less risky friendship networks than non-players, with attachment to school also higher in these two videogame play groups.

Allahverdipour et al. (2010) similarly found that middle-school students with moderate amounts of gameplay reported better mental health compared to non-gamers and excessive gamers. Gamers spent an average of $6.3 \mathrm{~h}$ per week playing video games with $47 \%$ reporting that they had played one or more intensely violent games including: Dead or Alive, Def Jam, Doom, Driver, Mortal Kombat, Grand Theft Auto, Resident Evil, and Prince of Persia. Moreover, 92\% of boys and 96\% of girls played video games although boys typically played games for greater duration than girls. However, it is the amount of gameplay that appears significant with moderate gaming among young men providing a healthy source of socialization, relaxation, and coping (Wack and Tantleff-Dunn, 2009). Defining "non-gamers" as those who did not play at all, "low" 1-6 h per week, "moderate" $7-10 \mathrm{~h}$ per week, and "excessive" as more than $10 \mathrm{~h}$ per week, the study found a curvilinear relationship between videogame playing and mental health outcomes with "moderate" gamers faring best (Allahverdipour et al., 2010). Although "excessive" gamers showed mild increases in problematic behaviors (such as somatic symptoms, anxiety, and insomnia, social dysfunction, and general mental health status), it was non-gamers who indicated the poorest outcomes on these constructs. Nongaming has been found to put boys, in particular, at greater risk for problems. This effect for non-gamers has also been reported by others who found gaming positively contributed to creative, social, and emotional benefits (Kutner and Olson, 2008).

There is concern that the potential benefits of videogames (including some games with violent content) have not received enough attention. Kutner and Olson (2008), co-directors of the Harvard Medical School Center for Mental Health and Media, recently found that boys who did not play any videogames during a typical week had a high risk of emotional disturbance. Boys have been found to use videogames for emotional regulation, to help them relax, to forget problems, or to feel less lonely (Kutner and Olson, 2008). While the survey, that formed part of this study, did find correlations between Mature-rated violent gameplay and some common childhood problems, such as aggressive behaviors or school problems, this risk was for both boys and girls. However, results did not show causality and most children who played violent games did not have problems. In fact many of the boys describe using violent videogames to manage their emotions and to deal with anger, frustration, and stress (Keyes, 2002; Kutner and Olson, 2008).

Videogames have also been reported to be used for stress relief. Game play for children has been used as a means of mood alteration or "letting off steam," following problems at school, or with friends, or with parents (Colwell, 2007). Furthermore, children have reported an understanding of the mood altering benefits of their videogame play and explicitly make choices to engage with 
videogames to manage their emotions. While videogame play has been associated with positive emotion, it has also been linked to immersive states of engagement.

\section{ENGAGEMENT}

Engagement within a task has been associated with increased happiness (Killingsworth and Gilbert, 2010). Engagement refers to an emotional involvement or commitment to some object or domain of interest and to the experiential intensity of a relationship or interaction. It also refers to one's temporal involvement or interactions with activities and social partners in the immediate environments with a strong relationship demonstrated between engagement and positive well-being (Shernoff, 2012). Intrinsically, interesting activities that evoke intense concentration and enjoyment have been described as creating flow or optimal engagement and experience (Csikszentmihalyi, 1998, 2008). Pointedly, videogame players commonly report optimal experiences reaching deeply "immersive" states of consciousness, in some cases growing to feel like they actually are their characters and really in the game (Snodgrass et al., 2011b). Csikszentmihalyi considered that flow would require many years of learning and skill development and that many would not experience flow. However, videogames through physical input, adjustment of difficulty, and real-time visual feedback, can provide near immediate and on demand flow experiences for their players (McGonigal, 2011).

This engagement with gaming has seen 9.6 million players of World of Warcraft (WoW), a massively multiplayer online (MMO) game (Stickney, 2013), collectively spend over six million years in the game. With the primary task within the game to improve oneself, players get a sense of blissful productivity (Bardzell et al., 2008). Players level up through completing quests to make their in-game avatar stronger, quicker, and better equipped. With these new skills and stronger character, players are able to take on more difficult quests and subsequent further leveling up. Leveling up can take in excess of $500 \mathrm{~h}$, and for many gamers this isn't the endgame but instead only the start of their engagement with WoW.

Part of the allure of WoW has been associated with the immersive experiences players report. Snodgrass et al. (2011a,b, 2012) examined different types of videogaming experiences and the effects they can have on players' lives, including their levels of stress, satisfaction, and happiness. Central was the premise that WoW and similar games can be thought of as new "technologies of absorption" and contemporary practices that can induce dissociative states in which players attribute dimensions of self and experience to in-game characters, with potential psychological benefit or harm (Snodgrass et al., 2011a). The Snodgrass study found that half of respondents reported WoW as increasing their happiness, that WoW helped them "relax and combat stress," and increased their "life satisfaction" (Snodgrass et al., 2011b). Two-thirds of their WoW respondents reported having at times immersive experiences.

Findings affirm that dissociation is positive and normal and that altered "absorbed" states of consciousness that many gamers reached (such as the "dissociative" identification some gamers have with their characters), provide some gamers with relaxation as well as some of the most satisfying, meaningful experiences of their lives (Snodgrass et al., 2011b, 2012). Experiences of "absorption-dissociation" explain the positive therapeutics of the game, which combines relaxation alternating with mildly stressinducing flow states (Snodgrass et al., 2011b). Positive stress helps players achieve "flow" and the experience of being in the "zone," as players are pushed by the game's tasks and challenges where there is likelihood of experiencing success. The two states of experience and consciousness are achieved if players imaginatively immerse themselves in this game-world and strongly identify with their character-avatars. This deep immersion can divert attention from real-world stress, allowing gamers to more readily reach deeply relaxed, even meditative, states of play (Snodgrass etal., 2011b). While the positive benefits of playing WoW have been described, the amount of game play can become problematic with time becoming a significant factor and influential on potential well-being outcomes. Again, the amount of gameplay has been found to be significant in moderating the potential well-being benefits (Durkin and Barber, 2002; Allahverdipour etal., 2010), making time spent in play a significant consideration for enhancing wellbeing.

\section{RELATIONSHIPS}

While immersive states have been associated with engagement in videogames, videogaming environments also provide opportunities to develop and maintain positive relationships. Positive relationships are considered highly important for the psychosocial adjustment and well-being of children, adolescents and adults (Bagwell and Schmidt, 2011). How positive relationships are defined is transitioning, as many young people form and maintain what they consider friendships online (Amichai-Hamburger et al., 2013). MMO gamers under the age of 18 have reported that the friendships they form online are comparable or better than their real-life friendships (Yee, 2006). WoW players report creating social capital through online gameplay with players using the game to extend real life relationships, meet new people and form relationships of varying strengths (Williams et al., 2006).

It has been argued that on-line communication is being used to enhance both the quantity and quality of communication between friends, leading to greater closeness and intimacy (Valkenburg and Peter, 2011). Playing online with friends who are also friends in real life can be healthy as interactions have helped regulate game play (Snodgrass et al., 2011a). Playing with real life friends has allowed players to transfer positive gaming experiences into real life. However, playing with real friends makes it harder to immerse, impacting on some of the stress reduction benefits although also potentially reducing the risk of problematic play and addiction. Playing with real life friends has also allowed players of WoW to share their experiences of success and achievement, to bolster and repair their feelings of worth and esteem as players. Players are then able to transfer ingame accomplishments and status to their real-life networks of friends and family. Playing WoW in this way creates cognitive and social bridges between online and offline worlds providing more objective perspective on MMO use and allowing better selfregulation. Therefore, playing with friends has the potential to affect levels of problematic play by mediating immersion and 
enhancing real-life relationships increasing social and psychological resilience (Colwell, 2007; Hull, 2009; Wack and Tantleff-Dunn, 2009; Snodgrass et al., 2011a; Trepte et al., 2012). The social interactions that occur within and outside of MMO play have been found to be highly social providing opportunities to create strong friendships and emotional relationships with a high percentage of gamers making life-long friends and partners (Yee, 2006; Cole and Griffiths, 2007).

Massively multiplayer onlines' are online "places" in which social interaction can occur and are unique in the fact that they collect and mix people pursuing goals in three-dimensional space (Williams et al., 2006). WoW is a vibrant social space for millions of players, populated with a range of social experiences ranging from ephemeral impersonal groups to sustained and deep relationships that extend offline. Games such as WoW include structure and rule sets impacting on what kinds of people play, what they do, and how and why they interact with one another. As part of gameplay social organizations are created with the design encouraging the formation of persistent player associations (Taylor, 2003).

Genres of videogames other than MMOs also offer opportunities for socializing with other players. For example firstperson-shooters and sport games almost always include online multiplayer modes that allow for both competitive and cooperative play. Similar modes are also sometimes included in action games, platforming games, puzzle games, and other genres. To this end, Johnson and Gardner (2010) found differing genres of games to result in varying experiences of autonomy but similar levels of competence and relatedness.

Positive relationships within online videogames have been associated with opportunities for social and emotional support. In a recent study, two-fifths of study participants said they would discuss sensitive issues with their online gaming friends that they would not discuss with their real life friends, with female players more likely to do this (Cole and Griffiths, 2007). Two-fifths of participants had met their online friends in real-life, suggesting that online videogaming is a social activity that facilitates social connections. A third of participants were attracted to another player ( $26 \%$ males compared to $42 \%$ females) suggesting that MMOs offer a safe environment for players to become emotionally involved with others. It would appear that videogames allow players to express themselves in ways they may not feel comfortable doing in real life because of their appearance, gender, sexuality, and/or age.

Online social videogames such as Words with Friends (WwF, 2013; similar to Scrabble) are encouraging families and friends to keep in touch. These games alert players to their turn and players can chat and/or leave messages for other players. In this manner, the game can be an excuse and mechanism for conversations to occur, with mothers and daughters discussing every day events and exchanging messages of affection. Playing these asynchronous games, where both players do not need to be online at the same time and can play their turn when convenient can encourage players to continue to exchange regularly (McGonigal, 2011). This "stickiness" (the ability of the game to keep the players playing) draws together the players to build and maintain positive relationships.

\section{MEANING}

Involvement in meaningful activities brings a sense of purpose and fulfillment to daily life. Finding purpose has been associated with involvement in activities which contribute to something larger than self. McGonigal (2011) reports that videogame players have a sense that they are part of something bigger than themselves. She details that in the final campaign in Halo 3, when gamers must protect the Earth from alien attack, players collective completed over 10 billion kills (achieved April 2009), at 12,000 kills a minute. Although there is no real value in killing an alien in Halo 3, McGonigal (2011) suggests that this does not mean they do not have meaning. Meaning is significant not just to ourselves, friends and family, but rather to a much larger group such as the whole Human race. Seligman (1998) suggests that the larger the group you attach yourself to, the more meaning you can derive. Connecting with millions of videogame players across the world, against a common in-game attack, is bigger than any one player and this has been associated with deriving meaning and subsequently well-being. As testament to the popularity of connecting with other players, in eight years of Halo 3 play, players compiled more than 123 billion hours of gaming, or more than 85 million days, achieving more than 136 billion kills and earning over 79 billion medals (in-game awards based on a player's actions during a typical multiplayer match) for their gaming.

Another example of players working together with purpose is evident when WoW players work together in guilds. They often participate in highly structured organizational experiences working towards common goals. Guilds can have relaxed social structures, known as "the tree house," or adopt highly structured, hierarchical organization known as "the barracks" (Williams et al., 2006). Players in formally structured guilds tend to have a more social experience than others. Playing WoW is thus like a team sport, which has its own rules, literal boundaries, and social norms (Williams et al., 2006). There are however, self-initiated tactics, team strategies, styles, and goals that make the play space a stage for socialization, organization, and networks. Some guilds rely on relatively haphazard policies and procedures, and are more likely to contain social tensions, misunderstandings, and fights. Guilds with clear policies and procedures manage tasks better and have generally happier members (John et al., 1991).

Videogames also have the potential to help eliminate loneliness. Even when friends and family are far away, videogames can allow players to interact, share, and be social (Pwn or Die Blog, 2009). Meeting online to play together in a game can provide strong social and emotional ties, and more meaning for society both within and beyond the game.

\section{ACCOMPLISHMENT}

Working towards goals and objectives to accomplish can contribute to a sense of achievement and satisfaction in life. This in turn contributes to feelings of competence and well-being. Ryan et al. (2006) suggested that the psychological "pull" of games is largely due to their capacity to engender feelings such as competence therefore enhancing psychological wellness. Competence is a psychological need for challenge and feelings of effectance. Therefore, factors that enhance the experience of competence (such as 
opportunities to acquire new skills or abilities, to be optimally challenged, or to receive positive feedback) enhance perceived competence. Competence is enhanced in gaming contexts where game controls are intuitive and readily mastered, and tasks within the game provide ongoing optimal challenges and opportunities for positive feedback (Ryan et al., 2006). Ryan et al. (2006) found the desire for future play was predicted by feelings of presence and players' self- determined needs for competence, autonomy, and relatedness.

In a similar manner to competence, accomplishment can also be linked to videogame play. To this end, Yee (2006) and Suznjevic and Matijasevic (2010) found accomplishment was an important motive for playing MMOs. Female players were more driven by the relationships and more likely to use the MMO environment to build supportive social networks, confirming findings reported by Cole and Griffiths (2007) and Snodgrass et al. (2011a), that online gaming can support positive relationships. However, male players were significantly more likely to be driven by accomplishment (Yee, 2006). The "achievement" factor measured the desire to become powerful in the context of the virtual environment through the achievement of goals and accumulation of items associated with power. While some users participated in the environment to make friends and form supportive social networks, others used the environment to become powerful through the accomplishment of goals.

Structured goal setting (i.e., incorporating factors of goal quality, Clark et al., 2009) has been shown to stimulate motivation and promote goal attainment (Locke, 1996). Goal attainment in turn is associated with significant benefits to health and well-being. Studies have found that goal progress enhances positive affect, improves life satisfaction and enhances general well-being (Carver and Scheier, 1990; Sheldon and Kasser, 1995; Ryan and Deci, 2000). This suggests that not only does goal progress enable a person to attain the target goal; it also produces general benefits to overall well-being. When structured goal setting is applied within tertiary mentoring programs students will not only improve their academic performance but will also experience enhanced general well-being.

Whereas accomplishments can be infrequent, unrecognized, and sometime unachievable in real-life, within the videogame accomplishments are regular, achievable and immediately rewarding. Videogames often have clear tasks to complete (e.g., quests), instructions to complete the task, and the task can be challenging but achievable, aligning with the player's current skill and experience. The player also receives immediate rewards and recognition when the task is completed (McGonigal, 2011). Players have a specific goal, an understanding of how to achieve the goal, the ability to complete the goal and importantly, the motivation to want to take on the goal. As Seligman (2004, p.40) argues "The most important resource building human trait is productivity at work." Game players can be highly productive in the games they play, accomplishing and achieving, and improving skills that contribute to positive experiences and enhanced self-worth.

\section{CONCLUSION}

As videogame play increases, we are moving towards a billion videogamers in the world. This review of the literature would suggest that videogame play has the potential to enhance life satisfaction and improve individual player's mental well-being. The inherent nature of videogames appears to promote and facilitate all aspects of Seligman's PERMA model, e g., Positive Emotion, Engagement, Relationships, Meaning and Accomplishment. Considering game play within this model suggests that play can have a positive effect on the mental health of individuals in society engaged in moderate videogaming.

Positive emotion contributes to the make-up of happiness and well-being. Literature provides links between positive mental wellbeing and play, providing illustrations of where game play provides a means of relaxation and stress reduction (Russoniello et al., 2009; Wack and Tantleff-Dunn, 2009; Snodgrass et al., 2011b). Although the amount of game play has been highlighted as a moderating factor, studies have shown that not playing videogames can result in the poorest well-being outcomes.

Engagement takes place when an experience becomes so absorbing that individuals completely lose sense of time. Achieving this state of flow or total engagement can be a natural outcome of being involved in activities they individuals love. Gaming activities that embody immense concentration and enjoyment have been described as creating flow or optimal experience (Csikszentmihalyi, 1998, 2008). Videogame players often report optimal experiences reaching deeply "immersive" states of consciousness (Snodgrass et al., 2011b) and leading to a sense of flourishing.

Relationships play a significant role in contributing to happiness and psychological health. Social relationships with strangers as well as with peers, siblings, parents, extended family, and friends are all sources of positive emotions and support. Online communication can enhance both the quantity and quality of communication between friends, leading to greater closeness and intimacy (Valkenburg and Peter, 2011) and young games have reported that the friendships they form online are comparable or better than their real-life friendships (Yee, 2006). In-game relationships offer social and emotion support, where players are able to discuss sensitive issues and exchange messages of affection.

Meaning, or belonging to, and serving something bigger than one's self, contributes to flourishing well-being. Happiness comes from creating and having meaning by attaching to something larger than oneself such as an interactive gaming environment. This experience instils a sense that there is a larger purpose to life, and that individuals are part of this meaning. Having connections with something bigger can also be an effective barrier against depression, with the larger the group to which you attach the more meaning you can derive (Seligman, 1998). Connecting with players across the world in a multiplayer videogame is bigger than any one player, fostering meaning and well-being.

Accomplishment includes having explicit goals in life, and achieving these is important to well-being and happiness. Achievement helps to build self-esteem and can provide a sense of accomplishment, strengthening self-belief. Games have a psychological "pull" largely due to their capacity to engender feelings such as competence and competence forms part of gameplay when game controls are intuitive and readily mastered with the task providing optimal challenges and opportunities for positive feedback. Whereas accomplishments can be infrequent, 
unrecognized, and sometime unachievable in real-life, within the videogame accomplishments are regular, achievable, and immediately rewarding.

This review presents literature to evidence how moderate levels of videogame play can have a positive influence on well-being. Specifically, videogame play has been found to lead to improved mood, reduced emotional disturbance, improve emotion regulation, relaxation, and stress reduction. Importantly, moderate play has been associated with better outcomes than either excessive play or a lack of play. There is a lack of negative impact for the majority of young players, and instead videogame play is associated with greater self-esteem regarding intelligence, computer skills, and mechanical ability. The experience of feelings of competence, autonomy and relatedness during videogame play has been linked with higher self-esteem and positive affect.

The research reviewed suggests that the experience of engagement while playing videogames can have a positive influence on well-being. However, it is excessive game play that can become problematic. This is supported by studies in this review that articulate how the amount of game play has been found to be significant in moderating the potential well-being benefits (see Durkin and Barber, 2002; Allahverdipour etal., 2010). This finding, however, should be considered in tandem with findings identifying the influence of the nature of engagement (harmonious or obsessive, Przybylski et al., 2009b) as well as the influence of pre-existing psychosocial vulnerability (Lemmens et al., 2011; Van Rooij et al., 2011).

Videogame research must move beyond a "good-bad" dichotomy and develop a more nuanced understanding about videogame play. Future research should attempt to identify the causal relationships, including bidirectional effects, between time spent on games, and positive, as well as negative outcomes. Furthermore, an exploration of whether time spent in game is associated with better outcomes such as depressed mood and loneliness is warranted. Evaluation of moderators such as gender and pre-existing psychosocial well-being are also vital to incorporate. Research is also needed to explore the possibility that games can be designed to moderate in-game time such that players achieve optimal well-being and flourishing.

\section{ACKNOWLEDGMENTS}

The authors thank the Young and Well Cooperative Research Centre (www.yawcrc.org.au) for their financial support of this project.

\section{REFERENCES}

Allahverdipour, H., Bazargan, M., Farhadinasab, A., and Moeini, B. (2010). Correlates of video games playing among adolescent in an Islamic country. BMC Public Health 10:286. doi: 10.1186/1471-2458-10-286

Amichai-Hamburger, Y., Kingsbury, M., and Schneider, B. (2013). Friendship: an old concept with a new meaning? Comput. Human Behav. 29, 33-39. doi: 10.1016/j.chb.2012.05.025

Anderson, C. A., Shibuya, A., Ihori, N., Swing, E. L., Bushman, B. J., Sakamoto, A., et al. (2010). Violent video game effects on aggression, empathy, and prosocial behavior in eastern and western countries: a meta-analytic review. Psychol. Bull. 136, 151-173. doi: 10.1037/a0018251

Bagwell, C. L., and Schmidt, M. E. (2011). The friendship quality of overtly and relationally victimized children. Merril Palmer Q. 57, 158-185. doi: 10.1353/mpq.2011.0009
Baranowski, T., Buday, R., Thompson, D., and Baranowski, J. (2008). Playing for real: video games and stories for health-related behavior change. Am. J. Prev. Med. 34, 74-82. doi: 10.1016/j.amepre.2007.09.027

Bardzell, S., Bardzell, J., Pace, T., and Reed, K. (2008). "Blissfully productive: grouping and cooperation in world of warcraft instance runs," in Proceedings of the 2008 ACM Conference on Computer Supported Cooperative Work (CSCW '08), (New York, NY: ACM), 357-360. doi: 10.1145/1460563. 1460621

Barr, P., Khaled, R., Noble, J., and Biddle, R. (2006). "Feeling strangely fine: the well-being economy in popular games," in Proceedings of the First International Conference on Persuasive Technology for Human Well-being (Berlin: Springer-Verlag Heidelberg), 60-71.

Boyle, E. A., Connolly, T. M., and Hainey, T. (2011). The role of psychology in understanding the impact of computer games. Entertain. Comput. 2, 69-74. doi: 10.1016/j.entcom.2010.12.002

Brand, J. (2012). Digital Australia (2012). National Research Prepared by Bond University for the Interactive Games and Entertainment Association. School of Communication and Media, Faculty of Humanities and Social Sciences, Bond University.

Bucolo, D. (2011). Violent video game exposure and physical aggression in adolescence: tests of the general aggression model. Diss. Abstr. Int. 71, 5180.

Burns, J., Webb, M., Durkin, L., and Hickie, I. (2010). Reach out central: a serious game designed to engage young men to improve mental health and wellbeing. Med. J. 192, S27-S30.

Carver, C. S., and Scheier, M. F. (1990). Origins and functions of positive and negative affect: a control-process view. Psychol. Rev. 97, 19-35. doi: 10.1037/0033295X.97.1.19

Chak, K., and Leung, L. (2004). Shyness and locus of control as predictors of internet addiction and internet use. Cyberpsychol. Behav. 7, 559-570. doi: 10.1089/cpb.2004.7.559

Clark, L., Lawrence, A. J., Astley-Jones, F., and Gray, N. (2009). Gambling nearmisses enhance motivation to gamble and recruit win-related brain circuitry. Neuron 61, 481-490. doi: 10.1016/j.neuron.2008.12.031

Cole, H., and Griffiths, M. (2007). Social interactions in massively multiplayer online role-playing gamers. Cyberpsychol. Behav. 10, 575-583. doi: $10.1089 /$ cpb.2007.9988

Colwell, J. (2007). Needs met through computer game play among adolescents. Pers. Individ. Dif. 43, 2072-2082. doi: 10.1016/j.paid.2007.06.021

Csikszentmihalyi, M. (1998). Finding Flow: The Psychology of Engagement with Everyday Life. New York: Basic Books.

Csikszentmihalyi, M. (2008). Flow: The Psychology of Optimal Experience. New York: Harper and Row.

Desai, R. A., Krishnan-Sarin, S., Cavallo, D., and Potenza, M. N. (2010). Video-gaming among high school students: health correlates, gender differences, and problematic gaming. Pediatrics 126:e1414. doi: 10.1542/peds. 2009-2706

Durkin, K., and Barber, B. (2002). Not so doomed: computer game play and positive adolescent development. J. Appl. Dev. Psychol. 23, 373-392. doi: 10.1016/S01933973(02)00124-7

Ferguson, C. J. (2007). The good, the bad and the ugly: a meta-analytic review of positive and negative effects of violent video games. Psychiatr. Q. 78, 309-316. doi: 10.1007/s11126-007-9056-9

Gee, J. P. (2008). "Learning and games," in The Ecology of Games: Connecting Youth, Games, and Learning, ed. K. Salen (Cambridge, MA: The MIT Press), 21-40.

Gentile, D. A. (2009). Pathological videogame use among youth 8 to 18: a national study. Psychol. Sci. 20, 594-602. doi: 10.1111/j.1467-9280.2009.02340.x

Gentile, D. A., and Gentile, J. R. (2008). Violent videogames as exemplary teachers: a conceptual analysis. J. Youth Adolesc. 37, 127-141. doi: 10.1007/s10964-0079206-2

Grüsser, S. M., Thalemann, R., and Griffiths, M. D. (2007). Excessive computer game playing: evidence for addiction and aggression? Cyberpsychol. Behav. 10, 290-292. doi: 10.1089/cpb.2006.9956

Hull, K. (2009). Computer/Video Games as a Play Therapy Tool in Reducing Emotional Disturbances in Children. Doctoral dissertation, UMI Number: 3380362, Liberty University, Lynchburg, VA.

Huppert, F., and So, T. T. (2013). Flourishing across Europe: application of a new conceptual framework for defining well-being. Soc. Indic. Res. 110, 837-861. doi: 10.1007/s11205-011-9966-7 
John, O. P., Donahue, E. M., and Kentle, R. L. (1991). The Big Five Inventory-Versions $4 a$ and 54. Berkeley, CA: University of California, Berkeley, Institute of Personality and Social Research.

Johnson, D., and Gardner, J. (2010). "Personality, motivation and video games," in The Proceedings of the 22nd Conference of the Computer-Human Interaction Special Interest Group of Australia on Computer-Human Interaction, OZCHI 2010, Brisbane, 276-279.

Johnson, L., Smith, R., Willis, H., Levine, A., and Haywood, K. (2011). The 2011 Horizon Report. Austin, TX: The New Media Consortium.

Keyes, C. L. M. (2002). The mental health continuum: from languishing to flourishing in life. J. Health Soc. Behav. 43, 207-222. doi: 10.2307/3090197

Killingsworth, M. A., and Gilbert, D. T. (2010). A wan-dering mind is an unhappy mind. Science 330, 932. doi: 10.1126/science.1192439

Ko, C., Yen, C., Yen, C., Yen, J., Chen, C., and Chen, S. (2005). Screening for internet addiction: an empirical research on cut-off points for the Chen Internet Addiction Scale. Kaohsiung J. Med. Sci. 21, 545-551. doi: 10.1016/S1607-551X(09)70206-2

Kutner, L., and Olson, C. K. (2008). Grand Theft Childhood: The Surprising Truth About Violent Video Games and What Parents Can Do. New York: Simon \& Schuster.

Lemmens, J., Valkenburg, P., and Peter, J. (2011). Psychosocial causes and consequences of pathological gaming. Comput. Human Behav. 27, 144-152. doi: 10.1016/j.chb.2010.07.015

Locke, E. A. (1996). Motivation through conscious goal setting, Appl. Prev. Psychol. 5, 117-124. doi: 10.1016/S0962-1849(96)80005-9

McGonigal, J. (2011). Reality is Broken: Why Games Make Us Better and How They Can Change the World. Sydney: Random House.

Möller, I., and Krahé, B. (2009). Exposure to violent videogames and aggression in German adolescents: a longitudinal analysis. Aggress. Behav. 35, 75-89. doi $10.1002 / a b .20290$

Przybylski, A. K., Ryan, R. M., and Rigby, C. S. (2009a). The motivating role of violence in video games. Personal. Soc. Psychol. Bull. 35, 243-259. doi $10.1177 / 0146167208327216$

Przybylski, A. K., Weinstein, N., Ryan, R. M., and Rigby, C. S. (2009b). Having to versus wanting to play: background and consequences of harmonious versus obsessive engagement in videogames. Cyberpsychol. Behav. 12, 485-492. doi $10.1089 /$ cpb.2009.0083

Przybylski, A. K., Weinstein, N., Murrayama, K., Lynch, M. F., and Ryan, R. M. (2011). The ideal self at play: the appeal of video games that let you be all you can be. Pscyhol. Sci. 23, 69-76. doi: 10.1177/0956797611418676

Pwn or Die Blog. (2009). 12 Ways Video Games Actually Benefit Real Life [Web log post]. Available at: http://www./pwnordie.com/blog/posts/15739 (accessed May 12, 2009).

Russoniello, C. V., O'Brien, K., and Parks, J. M. (2009). The effectiveness of casual video games in improving mood and decreasing stress. J. Cyber Ther. Rehabil. 2, 53-66.

Ryan, R. M., and Deci, E. L. (2000). Self-determination theory and the facilitation of intrinsic motivation, social development, and wellbeing. Am. Psychol. 55, 68-78. doi: 10.1037/0003-066X.55.1.68

Ryan, R. M., and Deci, E. L. (2008). From ego depletion to vitality: theory and findings concerning the facilitation of energy available to the self Soc. Personal. Psychol. Compass 2, 702-717. doi: 10.1111/j.1751-9004.2008. 00098.x

Ryan, R. M., Rigby, C. S., and Przybylski, A. (2006). The motivational pull of video games: a self-determination theory approach. Motiv. Emot. 30, 347-363 doi: 10.1007/s11031-006-9051-8

Seligman, M. (1998). Learned Optimism. New York: Pocket Books.

Seligman, M. (2004). Authentic Happiness. New York: Free Press.

Seligman, M. (2011). Flourish: A Visionary New Understanding of Happiness and Well- being. New York: Free Press.

Sheldon, K. M., and Kasser, T. (1995). Coherence and congruence: two aspects of personality integration. J. Pers. Soc. Psychol. 68, 531-543. doi: 10.1037/00223514.68.3.531

Sherry, J. (2004). Flow and media enjoyment. Commun. Theory 14, 328-347. doi: 10.1111/j.1468-2885.2004.tb00318.x

Sherry, J. (2007). "Violent video games and aggression: why can’t we find links?" in Mass Media Effects Research: Advances Through Meta-Analysis, eds R. Preiss, B. Gayle, N. Burrell, M. Allen, and J. Bryant (Mahwah, NJ: Lawrence Erlbaum Associates), 231-248
Shernoff, D. (2012). "Engagement and positive youth development: Creating optimal learning environments," in APA Educational Psychology Handbook, Vol. 2, Individual Differences and Cultural and Contextual Factors. APA Handbooks in Psychology, eds K. Harris, S. Graham, T. Urdan, S. Graham, J. Royer, and M. Zeidner (Washington, DC: American Psychological Association), 195-220.

Shibuya, A., Sakamoto, A., Ihori, N., and Yukawa, S. (2008). The effects of the presence and contexts of videogame violence on children: a longitudinal study in Japan. Simul. Gaming 39, 528-539. doi: 10.1177/1046878107306670

Snodgrass, J., Dengah, F., Lacy, M., Fagan, J., Most, D., Blank, M., et al. (2012). Restorative magical adventure or warcrack? Motivated MMO play and the pleasures and perils of online experience. Games Cult. 7, 13-28. doi: $10.1177 / 1555412012440312$

Snodgrass, J., Lacy, M., Dengah, F., and Fagan, J. (2011a). Enhancing one life rather than living two: playing MMO's with offline friends. Comput. Human Behav. 27, 1211-1222. doi: 10.1016/j.chb.2011.01.001

Snodgrass, J., Lacy, M., Dengah, F., Fagan, J., and Most, D. (2011b). Magical flight and monstrous stress: technologies of absorption and mental wellness in Azeroth. Cul. Med. Psychiatry 35, 26-62. doi: 10.1007/s11013-010-9197-4

Stickney, A. (2013). World of Warcraft down to 9.6 million subscribers. Available at: wow.joystiq.com/tag/wow-subscriber-numbers/ (accessed December 1, 2013).

Suznjevic, M., and Matijasevic, M. (2010). Why MMORPG players do what they do: relating motivations to action categories. Int. J. Adv. Media Commun. 4, 405. doi: 10.1504/IJAMC.2010.036838

Taylor, T. L. (2003). The Sopranos meets Everquest: socialization processes in massively multiusergames. Paper Presented at the Digital Arts and Culture (DAC) Streaming Wor $(l) d s$ Conference, Melbourne, VIC, Australia.

Trepte, S., Reinecke, L., and Juechens, K. (2012). The social side of gaming: how playing online computer games creates online and offline social support. Comput. Human Behav. 28, 832-839. doi: 10.1016/j.chb.2011.12.003

Valkenburg, P. M., and Peter, J. (2011). Online communication among adolescents: an integrated model of its attraction, opportunities, and risks. J. Adolesc. Health 48, 121-127. doi: 10.1016/j.jadohealth.2010.08.020

Van Rooij, A. J., Schoenmakers, T. M., Vermulst, A. A., van den Eijnden, R. J. J. M., and van de Mheen, D. (2011). Online videogame addiction: identification of addicted adolescent gamers. Addiction 106, 205-212. doi: 10.1111/j.1360-0443.2010.03104.x

Wack, E., and Tantleff-Dunn, S. (2009). Relationships between electronic game play, obesity, and psychosocial functioning in young men. Cyberpsychol. Behav. 12, 241-2444. doi: $10.1089 / \mathrm{cpb} .2008 .0151$

Wang, C. K., Khoo, A., Liu, W. C., and Divaharan, S. (2008). Passion and intrinsic motivation in digital gaming. Cyberpscyhol. Behav. 11, 39-45. doi: 10.1089/cpb.2007.0004

Williams, D., Ducheneaut, N., Xiong, L., Zhang, Y., Yee, N., and Nickell, E. (2006). From tree house to barracks: the social life of guilds in World of Warcraft. Games Cult. 1, 338-361. doi: 10.1177/1555412006292616

Words with Friends [WwF]. (2013). Words with Friends download page, Zygna mobile game developer, Retrieved from http://www.wordswithfriends.com/

World Health Organisation. (2001). World Health Report 2011: Mental Health, New Understanding, New Hope. Geneva: World Health Organisation.

Yee, N. (2006). Motivations for playing online games. Cyberpsychol. Behav. 9, 772775. doi: $10.1089 / \mathrm{cpb} .2006 .9 .772$

Conflict of Interest Statement: The authors declare that the research was conducted in the absence of any commercial or financial relationships that could be construed as a potential conflict of interest.

Received: 20 December 2013; accepted: 10 March 2014; published online: 31 March 2014.

Citation: Jones CM, Scholes L, Johnson D, Katsikitis M and Carras MC (2014) Gaming well: links between videogames and flourishing mental health. Front. Psychol. 5:260. doi: $10.3389 / f p s y g .2014 .00260$

This article was submitted to Developmental Psychology, a section of the journal Frontiers in Psychology.

Copyright (c) 2014 Jones, Scholes, Johnson, Katsikitis and Carras. This is an openaccess article distributed under the terms of the Creative Commons Attribution License (CC BY). The use, distribution or reproduction in other forums is permitted, provided the original author(s) or licensor are credited and that the original publication in this journal is cited, in accordance with accepted academic practice. No use, distribution or reproduction is permitted which does not comply with these terms. 